\title{
Conversion from cyclosporin A to tacrolimus is safe and decreases blood pressure, cholesterol levels and TGF- $\beta 1$ type I receptor expression
}

Baan CC, van Riemsdijk-van Overbeeke IC, Balk AHMM, Vantrimpont PMAJ, Mol WM, Knoop CJ, Niesters HGM, Maat LPWM, Weimar W. Conversion from cyclosporin A to tacrolimus is safe and decreases blood pressure, cholesterol levels and TGF- $\beta 1$ type I receptor expression.

Clin Transplant 2001: 15: 276-283. C Munksgaard, 2001

Abstract: To determine whether conversion from cyclosporin A (CsA) to tacrolimus (TAC)-based immunosuppressive therapy is safe and might lead to improvement in the clinical side effect profile we studied 55 cardiac allograft recipients. Ten stable patients were electively converted $(0.2-1.5 \mathrm{yr}$ after transplantation; group I) and 45 patients were converted on indication (0.5-14 yr after transplantation; group II). We studied blood pressure, cholesterol level and renal function in all patients. To unravel the mechanisms by which CsA may exert its toxic effects and to evaluate whether conversion is associated with immune activation, we analyzed the transforming growth factor (TGF)- $\beta 1$ system and intragraft interleukin (IL)-2 and IL-15 mRNA expression by real-time reverse transcription-polymerase chain reaction (RT-PCR) and quantitative flow cytometry in the selectively converted patients (group I).

Conversion did not result in immune activation as no clinical, histological or molecular signs of immune activation (increased intragraft IL-2 and IL-15 messenger RNA (mRNA) expression) leading to rejection were found. It did not improve renal function neither in patient group I nor in patient group II. However, after conversion the blood pressure decreased (group I: systolic $154 \pm 16$ vs $143 \pm 21 \mathrm{mmHg}, \mathrm{p}=0.03$, diastolic: $99 \pm 11$ vs $90 \pm 11, \mathrm{p}=0.02$ and group II: systolic $155 \pm 17$ vs $142 \pm 14, \mathrm{p}<0.001$, diastolic: $99 \pm 11$ vs $91 \pm 8 \mathrm{mmHg}, \mathrm{p}<0.001)$. Likewise, the cholesterol levels improved (group I: $6.6 \pm 0.5$ vs $5.7 \pm 0.3$ $\mathrm{mmol} / \mathrm{L}, \mathrm{p}=0.001$ and group II: $7.1 \pm 1.7$ vs $6.1 \pm 1.7 \mathrm{mmol} / \mathrm{L}, \mathrm{p}=$ $0.001)$. When patients were treated with TAC the ongoing rejections $(n=4)$ resolved and gum hyperplasia disappeared $(n=5)$. Conversion was associated with a two-fold lower TGF- $\beta 1$ type I receptor expression on peripheral lymphocytes and monocytes $(\mathrm{p}=0.02$ and $\mathrm{p}=0.002$, respectively).

Conversion from CsA to TAC results in improvement of blood pressure and cholesterol levels and does not induce immune activation. These beneficial effects were accompanied with lower TGF- $\beta 1$ type I receptor expression.

\author{
Carla C Baan ${ }^{a}$, Iza C van \\ Riemsdijk-van Overbeeke ${ }^{a}$, \\ Aggie HMM Balk ${ }^{\text {, }}$ Pascal \\ MAJ Vantrimpont ${ }^{\mathrm{b}}$, Wendy \\ M Mola $^{\mathrm{a}}$, Chris J Knoop ${ }^{\mathrm{a}}$, \\ Hubert GM Niesters ${ }^{c}$, Lex \\ PWM Maat ${ }^{\mathrm{d}}$ and \\ Willem Weimar ${ }^{a}$
}

Departments of a Internal Medicine, ${ }^{\mathrm{b}}$ Cardiology, ${ }^{\mathrm{c}}$ Diagnostic Institute of Molecular Biology, ${ }^{d}$ Thoracic Surgery, Erasmus Medical Centre, Rotterdam, The Netherlands

Key words: conversion - cyclosporin A heart transplantation - tacrolimus - TGF- $\beta$

Corresponding author: Carla C Baan, Erasmus Medical Center Rotterdam, Department of Internal Medicine, Dr Molewaterplein 40, Room BD 299, 3015 GD Rotterdam, The Netherlands. Tel: +31 10 4635420; fax: + 3110 4635430; e-mail: baan@inw1.azr.nl

Accepted for publication 6 April 2001
After the introduction of cyclosporin A (CsA) the results of clinical heart transplantation significantly improved. Therefore, most immunosuppressive regimens are CsA based (1). CsA affects T-cell function at the level of messenger RNA (mRNA) transcription of various cytokines, and in particu- 
lar of interleukin (IL)-2, which is critical for T-cell proliferation and maturation. Unfortunately, chronic treatment with CsA is associated with CsA-specific side effects, e.g. hyperlipidemia, hypertension, nephrotoxicity, hirsutism and gingivall hypertrophy (2-6). The mechanisms by which CsA treatment induces these side effects are not completely understood but it is known that CsA increases mRNA levels for a number of genes involved in cholesterol biosynthesis and hypertension $(2,7)$. Hypertension can be the result of an abnormal sodium and water balance, endothelinmediated systemic vasoconstriction and impaired vasodilatation secondary to reduction in nitric oxide $(6,7)$. CsA can, by inducing lipid metabolism disorders and hypertension, contribute to the development of allograft vasculopathy, a complication affecting many cardiac allograft recipients at the long term $(1,8)$. Nephrotoxicity is the third important side effect related to chronic CsA treatment. Two pathophysiologic mechanisms have been postulated by which CsA may exert its nephrotoxic effect. First, a vasomotor component of afferent arteriolar constriction reducing the glomerular perfusion, and second by replacement of vascular smooth muscle cells by hyaline material and the induction of interstitial fibrosis (9). Furthermore, hirsutism and gum hypertrophy are troublesome side effects commonly associated with the use of CsA.

Several studies have demonstrated that CsA stimulates cytokines, such as transforming growth factor (TGF)- $\beta 1(10,11)$. For instance, in CsAtreated animals with chronic nephropathy an association was found between the characteristic histological abnormalities in the kidney and increased renal expression of TGF- $\beta 1(12,13)$. Also hypertension and transplant coronary artery disease have been associated with elevated TGF- $\beta 1$ levels $(14,15)$.

Primary treatment with tacrolimus (TAC), a more recently introduced calcineurin inhibitor that has a comparable mode of action to that of CsA, has been shown to be more effective in the treatment of ongoing rejection (16). Furthermore, both single- and multi-center trials have shown that treatment with TAC is accompanied with less hyperlipidemia and hypertension (17-19). In these studies it appeared that TAC also has nephrotoxic properties shown by renal dysfunction in TACtreated cardiac allograft recipients. However, conversion studies from CsA to TAC in kidney allograft recipients showed that TAC treatment could significantly improve renal function $(16,20$, 21).
The aim of this study was two-fold, first to assess if the conversion from CsA to TAC is associated both with immune activation and with improvement in CsA-related side effects in patients with cardiac transplantation and second, to analyze the involvement of growth factors and cytokines as underlying mechanisms related to the production of CsA toxic effects.

\section{Material and methods}

Patients

In 10 stable cardiac allograft recipients $(9$ males and 1 female, mean age $51.8 \mathrm{yr}$, range $16-60 \mathrm{yr}$; group I) time after transplantation $185 \mathrm{~d}$ (mean, range 60-450 d), we evaluated the effect of conversion from CsA to TAC. In these patients (group I) we studied the clinical parameters: blood pressure, renal function, and cholesterol level and the immunological parameters: intragraft IL-2 and IL-15 mRNA expression, and the TGF- $\beta$ system. Fortyfive cardiac allograft recipients (35 males and 10 females, mean age $48.8 \mathrm{yr}$, range $15-67 \mathrm{yr}$; group II) were converted from CsA to TAC because of hypertension $(\mathrm{n}=27)$, hypercholestemia $(\mathrm{n}=7)$, ongoing acute rejection $(\mathrm{n}=4)$, gingival hyperplasia $(n=5)$ and general malaise $(n=2)$. Mean time after transplantation of these patients was 5.5 yr (range 0.5-14 yr). Maintenance immunosuppressive therapy consisted of CsA, prednisolone in all patients. In group II, 14 out of 45 patients also received the immunosuppressant mycophenolate mofetil.

All patients were on atorvastatin or pravastatin. Hypertension (systolic $\geq 150 \mathrm{mmHg}$ and/or diastolic $\geq 100 \mathrm{mmHg}$ ) was treated by calcium-entry blockers (first choice) or angiotensis-converting enzyme (ACE) inhibition (second choice). In some patients, central working anti-hypertensive drugs had to be added. Comparable anti-hypertensive regimens were given to patients who were converted early or at a later time point after transplantation. Rejection was histologically diagnosed and graded according to the criteria of the International Society for Heart and Lung Transplantation (22). Anti-rejection therapy consisted of $1 \mathrm{~g}$ of methylprednisolone i.v. for 3 consecutive days. Frequently recurring or refractory rejection episodes were treated with rabbit-ATG.

\section{Real-time reverse transcription (RT)-PCR}

We used the real-time reverse transcription-polymerase chain reaction (RT-PCR) technique to quantify the amount of IL-2, IL-15, TGF- $\beta 1$ and glyceraldehyde phosphate dehydrogenase 
(GAPDH) mRNA expression in endomyocardial biopsy taken before $(\mathrm{n}=15)$ and after conversion $(\mathrm{n}=11)$ from patient group I. Messenger RNA extraction and cDNA transcription were performed as described in detail previously (23). The real-time reverse transcriptase polymenase chain reaction (RT-PCR) technique is based on the use of the $5^{\prime}$ nuclease activity of Taq DNA polymerase to cleave a nonextendable dual-labeled fluorogenic hybridization probe during the extension phase of PCR. The probe is labeled with a reporter fluorescent dye at the $5^{\prime}$ end and a quencer fluorescent dye at the $3^{\prime}$ end. Cleavage of the probe results in an increase in reporter flourescence at each cycle. Real-time PCR reactions are characterized by the point during cycling when amplification of the PCR product is first detected: the threshold cycle $\left(C_{\mathrm{t}}\right)$ that is defined as the fractional cycle number at which the flourescence generated by cleavage of the probe passes above baseline. The target message in endomyocard biopt (EMB) is quantified by measuring $C_{\mathrm{t}}$ and by using a standard curve using serial dilutions of a known amount of standard RNA. The choice of primer and probe (IL-2, IL15) was defined using the primer express software (PE Biosystems, Norwalk, CT, USA). Nucleotide sequences for the oligonucleotide primers and probes are the following: IL-2 sense primer: $5^{\prime}$ TTT GAA TGG AAT TAA TAA TTA CAA GAA TCC 3', IL-2 anti-sense primer: 5' TTC TAG ACA CTG AAG CTG TTT CAG TTC, IL-2 probe 5' CCA GGA TGC TCA CAT TTA AGT TTT ACA TGC CC 3'; IL-15 sense primer: 5' TGG GTG AAT GTA ATA AGT GAT TTG AAA 3', IL-15 anti-sense primer: 5' AAC TCC AAG AGA AAG CAC TTC ATT G 3', IL-15 probe 5' TTT ATA TAC GGA AAG TGA TGT TCA CCC CAG TTG C 3'. Pre-developed Taqman ${ }^{\circledR}$ PDAR assays were used to measure TGF- $\beta 1$ and the house keeping gene GAPDH concentrations (PE Biosystems). GAPDH was used in each sample to control sample-to-sample variations in mRNA concentrations.

Five microliters of cDNA was added to $45 \mu \mathrm{L}$ of PCR mixture containing $25 \mu \mathrm{L}$ of Universal PCR Master Mix (PE Biosystems), $1 \mu \mathrm{L}$ of sense primer $(50 \mathrm{pmol}), 1 \mu \mathrm{L}$ of anti-sense primer $(50 \mathrm{pmol}), 1$ $\mu \mathrm{L}$ of FAM labeled probe (10 pmol), and $17 \mu \mathrm{L}$ of $\mathrm{H}_{2} \mathrm{O}$. The PCR reaction was performed after a first step of $2 \mathrm{~min}$ at $50^{\circ} \mathrm{C}$ and $10 \mathrm{~min}$ at $95^{\circ} \mathrm{C}$ by 40 cycles of $15 \mathrm{~s}$ at $95^{\circ} \mathrm{C}$ and $1 \mathrm{~min}$ at $58^{\circ} \mathrm{C}$ (IL-2, IL-15) or $60^{\circ} \mathrm{C}$ (TGF- $\beta 1$, GAPDH) using the ABI Prism 7700 sequence detector (PE Biosystems). All experiments were performed in duplicate. The relative concentration of intragraft IL-2, IL-15 and TGF- $\beta 1$ was divided by the relative concentration of GAPDH. This represents the amount of target mRNA transcript corrected for the amount of mRNA used for RT and the efficacy of each reaction.

\section{Flow cytometry}

Whole blood ethylenediaminetetracetic acid (EDTA) samples were monitored for the presence of monocytes (CD14 positive) and lymphocytes (TCR $\alpha \beta$ positive). Surface markers were analyzed by two-color cytometry using mAbs conjugated to fluorescein isothiocyanate (FITC) or phycoerythrin (PE). Quantitative flow cytometry was performed as described previously (24). Briefly, cells were stained with monoclonal antibodies directed to CD14 (Immunotech, Marseille, France), as the marker for monocytes, and WT31 (Immunotech) as the marker for TCR $\alpha \beta$ positive cells, i.e. T-cells. In both monocytes and T-cells, TGF- $\beta$ type I and type II receptors were monitored. For TGF- $\beta$ type I receptor a two-step staining was used. After the first step with TGF- $\beta$ type I receptor antibodies (30 min at $4^{\circ} \mathrm{C}$ ), the cells were washed three times with $2 \mathrm{~mL}$ Hanks-Balanced Salt Solution (HBSS) (Gibco, Paisley, Scotland) supplemented with 1\% bovine serum albumin (BSA) (Sigma, St. Louis, MO, USA) and $0.1 \%$ sodium azide, followed by incubation with sheep-anti-rabbit IgG conjugated with $\mathrm{PE}$ for $30 \mathrm{~min}$ at $4^{\circ} \mathrm{C}$ Sanver Tech (Santa Cruz Biotechnology, Inc, Santa Cruz, CA, USA). The antibody staining for TGF- $\beta$ type II receptor was directly conjugated to PE Sanver Tech (Santa Cruz Biotechnology, Inc, Santa Cruz, CA, USA).

The staining procedure was performed by incubating $100 \mu \mathrm{L}$ whole blood with the above-mentioned monoclonal antibodies. After staining the red blood cells were lysed with FACS lysing solution (B\&D) during $10 \mathrm{~min}$. Samples were centrifugated and washed twice in cell Pack (TOA, Hamburg, Germany). Flow cytometric analysis was performed on a FACscan flow cytometer using Cell Quest software (B\&D). From each tube 10000 events in the gate were measured. To compare different flow cytometric assays in time we calibrated the flow cytometer using specific Calibration Beads (Calibration Beads Quantum 1000, Flow cytometer Standards Corp, San Jose, PR). Each bead contains a known amount of fluorochrome. The intensity of the flourescence is converted to a standard curve by the Quick Cal Program for Quantum Beads (B\&D). The mean flourescence is denoted as molecular equivalents of soluble fluorochrome (MESF). Peripheral blood cells from healthy subjects $(\mathrm{n}=12)$ served as controls (4 males, mean age $30 \mathrm{yr}$, range $24-52 \mathrm{yr}$ ). 


\section{Statistical analysis}

Differences in distribution before and after conversion were assessed using the paired two-way variance test (paired Student's $t$-test). A level of $\mathrm{p} \leq 0.05$ was considered to indicate statistical significance.

\section{Results}

\section{Clinical data}

We studied the effect of conversion from CsA to TAC in two cohorts of cardiac allograft recipients. Patients without overt CsA-related side effects $(\mathrm{n}=10$, group I) and those with CsA-related side effects $(n=45$, group II). Clinical parameters studied in both cohorts included blood pressure, renal function and lipid levels.

Before conversion the mean whole blood trough CsA level for group I (no overt CsA-related side effects, mean time after transplantation $185 \mathrm{~d}$ ) was $250 \pm 65$ and for group II (patients with CsA-related side effects, mean time after transplantation $5.5 \mathrm{yr})$ was $136 \pm 57 \mathrm{ng} / \mathrm{mL}$. After conversion the mean TAC trough level of these patients was $15.0 \pm 3.8 \mathrm{ng} / \mathrm{mL}$ (group I) and $8.8 \pm 2.7 \mathrm{ng} / \mathrm{mL}$ (group II). Concurrent medication was not changed.

Five out of 45 patients with overt CsA-related side effects (group II) were converted to TAC because of gum hypertrophy and 4 patients because of ongoing rejection episodes. The gum hypertrophy disappeared and the ongoing rejection resolved when patients received TAC. Conversion to TAC did not lead to histologically proven acute rejection episodes in any of the studied patients without signs of rejection at time of conversion.

Table 1 summarizes the results of the clinical parameters studied of the patients: blood pressure, renal function and lipid levels. For patient group I, converted to TAC within 2 yr after transplantation, and group II, patients who were switched to TAC because of CsA induced side effects, no positive effect of the conversion on renal function was found. The serum creatinine levels were comparable before and after conversion group I: $145 \pm 43$ vs $128 \pm 28 \mu \mathrm{mol} / \mathrm{L}, \mathrm{p}=0.10$, and group II $162 \pm$ 56 vs $160 \pm 68 \mu \mathrm{mol} / \mathrm{L}$, respectively, $\mathrm{p}=0.72$. In contrast, a significant improvement on both blood pressure (systolic and diastolic) and total cholesterol levels was observed. Already at 8 wk after conversion, the systolic blood pressure of patient group I decreased from $154 \pm 16$ to $143 \pm 21$ $\mathrm{mmHg}$ and the diastolic blood pressure from $99 \pm$ 11 to $90 \pm 11 \mathrm{mmHg}(\mathrm{p}=0.03$ and $\mathrm{p}=0.02$, respectively), and for group II from $155 \pm 17$ to $142 \pm 14 \mathrm{mmHg}$ (systolic) and $99 \pm 11$ to $91 \pm 8$ $\mathrm{mmHg}$ (diastolic) $(\mathrm{p}<0.001$ and $\mathrm{p}<0.001$, respectively). Total cholesterol levels improved for patient group I from $6.6 \pm 0.4$ to $5.7 \pm 0.3 \mathrm{mmol} / \mathrm{L}$ $(\mathrm{p}=0.001)$, and for patient group II from $7.1 \pm 1.7$ to $6.1 \pm 1.7 \mathrm{mmol} / \mathrm{L}(\mathrm{p}<0.001)$.

Cytokine and cytokine receptor expression before and after conversion

Intragraft $m R N A$ expression of IL-2, IL-15 and $T G F-\beta 1$ by real-time $R T-P C R$. We used the highly

Table 1. Effects of conversion from CsA to TAC on blood pressure, renal function and lipid levels

\begin{tabular}{|c|c|c|c|}
\hline & Before conversion & After conversion & $p$ value ${ }^{1}$ \\
\hline \multicolumn{4}{|l|}{ Patient group I $(n=10)^{2}$} \\
\hline CsA tough level (ng/mL) & $250 \pm 65$ & & \\
\hline TAC trough level (ng/mL) & & $15.0 \pm 3.8$ & \\
\hline \multicolumn{4}{|l|}{ Blood pressure } \\
\hline Systolic RR (mmHg) & $154 \pm 16$ & $143 \pm 21$ & 0.03 \\
\hline Diastolic RR (mmHg) & $99 \pm 11$ & $90 \pm 11$ & 0.02 \\
\hline Serum creatinine $(\mu \mathrm{mol} / \mathrm{L})$ & $145 \pm 43$ & $128 \pm 28$ & 0.10 \\
\hline Total cholesterol (mmol/L) & $6.6 \pm 0.5$ & $5.7 \pm 0.3$ & 0.001 \\
\hline \multicolumn{4}{|l|}{ Patient group $\|(n=45)^{3}$} \\
\hline CsA trough level (ng/mL) & $136 \pm 57$ & & \\
\hline TAC trough level (ng/mL) & & $8.8 \pm 2.7$ & \\
\hline \multicolumn{4}{|l|}{ Blood pressure } \\
\hline Systolic RR (mmHg) & $155 \pm 17$ & $142 \pm 14$ & $<0.001$ \\
\hline Diastolic RR (mmHg) & $99 \pm 11$ & $91 \pm 8$ & $<0.001$ \\
\hline Serum creatinine $(\mu \mathrm{mol} / \mathrm{L})$ & $162 \pm 56$ & $160 \pm 68$ & 0.72 \\
\hline Total cholesterol (mmol/L) & $7.1 \pm 1.7$ & $6.1 \pm 1.7$ & 0.001 \\
\hline
\end{tabular}

\footnotetext{
${ }^{1}$ Paired Student's $t$-test.

2 Patients (group I, described in detail in the Material and methods) who were converted from CsA to TAC within the first 2 post-operative years.

${ }^{3}$ Patients (group II, described in detail in the Material and methods) who were converted from CsA to TAC because of CsA toxicity.
} 


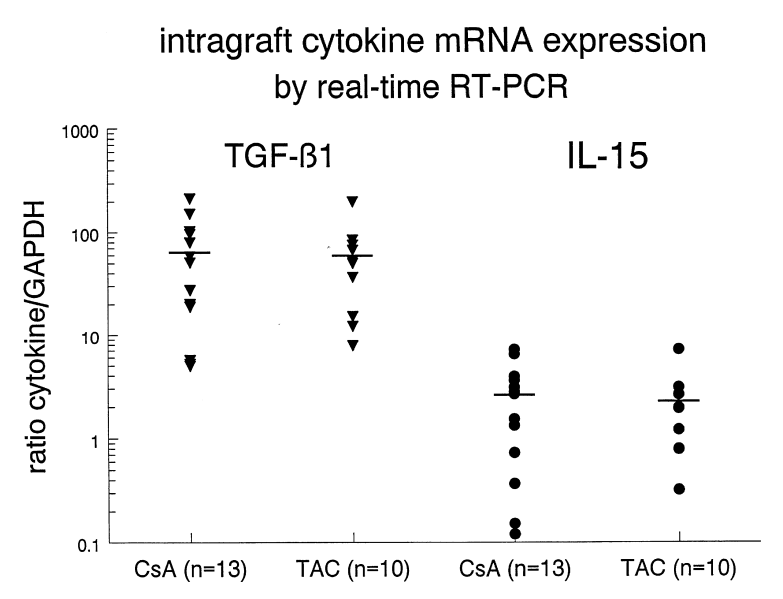

Fig. 1. Messenger RNA expression levels of TGF- $\beta 1$ and IL-15 measured in endomyocardial biopsies real-time RT-PCR from patient group I before and after conversion from CsA to TAC. No significant differences were found in intragraft mRNA expression levels for TGF- $\beta$ and IL-15 before and after conversion.

reproducible real-time RT-PCR to quantify intragraft IL-2, IL-15, and TGF- $\beta 1$ mRNA expression in endomyocard biopt (EMB) from stable cardiac allograft recipients $(n=10$, group I) before $(n=$ $15)$ and after conversion at 8 wk (mean, $\mathrm{n}=11)$ from CsA to TAC.

There was no difference in intragraft cytokine mRNA expression levels before and after conversion. Comparable intragraft TGF- $\beta 1$ and IL-15 mRNA levels were measured (Fig. 1). The expression of IL-2, the cytokine associated with immune reactivity, was only detectable in 2/26 EMB. One specimen was positive during CsA treatment and one specimen during TAC treatment.

Peripheral expression of TGF- $\beta 1$ type $I$ and II receptors by quantitative flow cytometry. To assess the effects of immunosuppressive medication on the expression level of TGF- $\beta 1$ receptors on peripheral T-lymphocytes (TCR $\alpha \beta$ positive) and monocytes (CD14 positive) we used quantitative flow cytometry. The analysis was exclusively performed on peripheral blood samples from patient group I.

Only a few TCR $\alpha \beta$ lymphocytes stained positive for the type I and type II TGF- $\beta 1$ receptors, $2.1 \pm$ $2.2 \%$ and $2.2 \pm 2.7 \%$ (mean $\pm \mathrm{SD}$ ), respectively. The proportion of CD14 positive cells with TGF$\beta 1$ type I receptors was $44.6 \pm 28.5 \%$ and with type II receptors $8.7 \pm 7.2 \%$. For TGF- $\beta 1$ type I and type II receptors these percentages on TCR $\alpha \beta$ positive and CD14 positive peripheral blood cells were not influenced by the conversion to TAC. However, conversion did affect the expression level of TGF- $\beta 1$ type I receptor and not of TGF- $\beta 1$ type
II receptor (Fig. 2). On both TCR $\alpha \beta$ positive lymphocytes and CD14 positive cells the membrane bound expression of TGF- $\beta 1$ type I receptor significantly decreased. Before conversion, during CsA treatment the expression of the TGF- $\beta 1$ type I receptor on TCR $\alpha \beta$ positive lymphocytes was MESF $9718 \pm 4947$ (mean \pm SD) which decreased to MESF $6406 \pm 2886$ after conversion to TAC, and on CD14 positive monocytes from MESF $15263 \pm 6979$ to MESF $8012 \pm 6181(\mathrm{p}=0.02$ and $\mathrm{p}=0.002$, respectively).

\section{Discussion}

In the present study, we have analyzed the consequences of conversion from CsA to TAC on both clinical and immune parameters of cardiac allograft recipients. Shortly after transplantation, within 2 yr (patient group I) the conversion to TAC resulted in improvement of blood pressure and cholesterol levels. This improvement in the studied clinical parameters was also seen in patients who were switched to the immunophilin TAC because of severe CsA toxicity. Even, as long as 14-yr post-transplant patients may benefit from conversion from CsA to TAC concerning hypertension, hypercholestemia and gum hyperplasia. Furthermore, the ongoing rejections resolved when patients were treated with TAC. These beneficial effects were accompanied with decreased expression of TGF- $\beta$ type I receptor on peripheral mononuclear blood cells. Furthermore, a change in the immunosuppressive protocol did not lead to immune activation, neither histological signs of acute rejection nor increased IL-2 or IL-15 mRNA expression in EMB were seen.

Hyperlipidemia, hypertension and renal failure are very common following heart transplantation and the prevalence increases with time after transplantation (1). These complications are important non-immunologic risk factors in allograft recipients. High lipid levels may contribute to the onset and/or progression of chronic rejection, while renal insufficiency has a high impact on the mortality of the cardiac allograft recipients $(1,5)$. These and other complications are often related to chronic CsA treatment that can exert its adverse effects by disturbed cytokine production $(10,11)$. Therefore, the beneficial effects seen in our and other conversion studies might be the result of restored physiological levels of TGF- $\beta 1$, a cytokine known for its role in CsA toxicity $(12,14,17-19)$. Recently, we could indeed show that TGF- $\beta 1$ plays a role in renal insufficiency in our CsA-treated cardiac allograft recipients as we found an association between TGF- $\beta 1$ codon 10 genotypes and renal dysfunction 


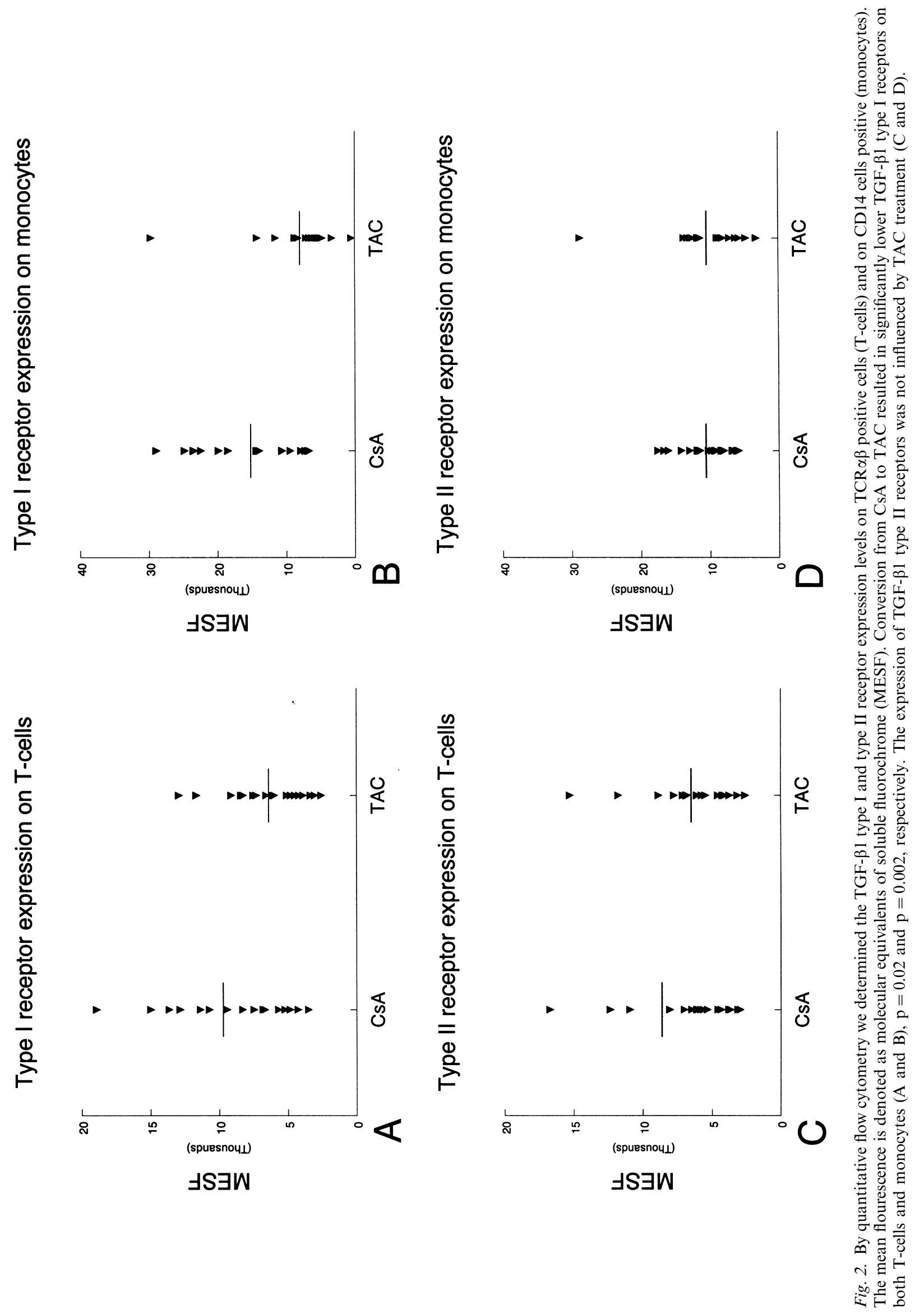


(serum creatinine $\geq 250 \mu \mathrm{mol} / \mathrm{L}$ ) (25). In the present study, no effect of conversion was seen on the intragraft mRNA expression level of TGF- $\beta$ (Fig. 1) as the activation of this particular cytokine is regulated at the protein level (26). Therefore, a possible relationship between TGF- $\beta$ expression and CsA toxicity can be found by analyzing active TGF- $\beta 1$ protein levels. In that prospect it is important to study both the TGF- $\beta$ expression by parenchymal cells and graft infiltrating cells.

Cytokines act on target cells through high affinity membrane receptors. The active form of TGF- $\beta 1$ binds to the TGF- $\beta$ type I and type II receptors, which are signaling mediators (26). Nowadays, patients are often treated with the immunosuppressant TAC, a calcineurin inhibitor that competes with TGF- $\beta$ type I receptor for FKBP12 interaction $(26,27)$. FKB12 is a binding protein for TAC (i.e. FK506). Thus, association of FKBP12 with TGF- $\beta$ type I receptor decreases receptor signaling. In the present conversion study from CsA to TAC we confirmed that treatment with TAC reduced TGF- $\beta$ type I receptor expression on peripheral blood cells. Also primary treatment with TAC is not associated with increased production of TGF- $\beta 1(28,29)$. These findings may explain why cardiac allograft recipients on a TAC-based immunosuppressive regimen have less hypertension and hyperlipidemia, and better renal function than patients treated with CsA (17-19).

In our patient population, conversion from CsA to TAC did resolve the ongoing rejections and resulted in significant improvement of systolic and diastolic blood pressure and lipid levels and the gum hypertrophy disappeared even after years of chronic CsA treatment. The beneficial effects of replacement of CsA by TAC on plasma cholesterol levels might be the result of shutting of the key gene involved in cholesterol biosynthesis, i.e. sterol regulatory element-binding protein (SREBP)-2 (2). However, despite improved blood pressure the conversion did not improve renal function reflecting either comparable intrarenal vasoconstriction based nephrotoxicity of both CsA and TAC leading to diminished glomerular filtration rate or structural kidney damage induced by long-term CsA therapy. Renal insufficiency induced by CsA is characterized by interstitial fibrosis, tubular atrophy and glomerular vascular lesions (30).

We conclude that conversion from CsA to TAC is of benefit for cardiac allograft recipients even for patients who were on CsA for years. The change in immunosuppressive regimen was associated with decreased TGF- $\beta 1$ type I receptor expression on peripheral mononuclear blood cells, suggestive for the involvement of TGF- $\beta 1$ in CsA-related complications.

\section{References}

1. Hosenpud JD, Bennett Le, Keck BM, Fiol B, Boucek MM, Novick RJ. The Registry of the International Society for Heart and Lung Transplantation: Sixteenth Official Report 1999: 18: 611.

2. Wu J, Zhu H, Patel SB. CsA-induced dyslipoproteinemia is associated with selective activation of SREBP-2. Am Physiol Soc 1999: 277: E1087.

3. Versluis DJ, Wenting GJ, Weimar W. Alterations in lipid and carbohydrate metabolism attribute to CsA A in renal transplants (letter). Br Med J 1986: 292: 272.

4. Ozdogan E, Banner N, Fitzgerald M, Musumeci F, KhaGHANi A, Yacoub M. Factors influencing the development of hypertension following cardiac transplantation. J Heart Transplant 1990: 5: 548.

5. Gelder van T, Balk AHMM, Zietse R et al. Renal Insufficiency after heart transplantation: a case control study. Nephrol Dial Transplant 1998: 13: 2322.

6. Jenkins GH, Singer DRJ. Hypertension in thoracic transplant recipients. J Human Hypertension 1998: 12: 813.

7. Ventura ho, Malik FS, Mehra MR, Stapleton DD, SMART FW. Mechanisms of hypertension and the role of CsA. Curr Opin Cardiol 1997: 12: 375.

8. BALK AHMM, Weimar W. Chronic heart graft rejection in the clinical setting. In: Paul LC, Solez K, eds. Organ Transplantation. New York: Marcel Dekker, 1992: 187195.

9. KAHAN BD. An immunosuppressive triumvirate to minimize renal injuries associated with calcineurin antagonist therapy. Transplantation 1999: 68: 12.

10. Shin G-T, Khanna A, Ding R et al. In vivo expression of transforming growth factor- $\beta 1$ in humans: stimulation by CsA. Transplantation 1998: 65: 313.

11. Khanna A, Kapur S, Sharma V, Li B, Suthantriran M. In vivo hyperexpression of transforming growth factor$\beta 1$ in mice: stimulation by CsA. Transplantation 1997: 63: 1037.

12. Shinab FS, Andoh TF, TAnner AM et al. Role of transforming growth factor- $\beta 1$ in experimental chronic CsA nephropathy. Kidney Int 1996: 49: 1141.

13. Khanna AK, Cairns VR, Becker CG, Hosenpud JD. Transforming growth factor (TGF)- $\beta$ mimics and antiTGF- $\beta$ antibody abrogates the in vivo effects of CsA. Transplantation 1999: 67: 882.

14. Li B, Khanna A, Sharma V, Sing T, Suthanthiran M, August P. TGF- $\beta 1$ DNA polymorphisms, protein levels, and blood pressure. Hypertension 1999: 33: 271.

15. De Groot-Kruseman HA, BaAn CC, Mol WM et al. Intragraft platelet-derived growth factor- $\beta$ and transforming growth factor- $\beta 1$ during the development of accelerated graft vascular disease after clinical heart transplantation. Transplant Immunol 1999: 7: 201.

16. Jordan ML, NARAghi R, Shapiro R et al. Tacrolimus for rescue of refractory renal rejection. Transplant Proc 1998: 30: 1257.

17. Reichart B, Meiser B, Vigano M et al. European multicenter tacrolimus (FK506) heart pilot study: one-year results - European TAC multicenter heart study group. J Heart Lung Transplant 1998: 17 (8): 775.

18. TAYlor DO, BARr ML, Radovancevic B et al. A randomised, multicenter comparison of TAC and CsA immunosuppressive regimens in cardiac transplantation: decreased hyperlipidemia and hypertension with TAC. J Heart Lung Transplant 1999: 18 (4): 336. 
19. Reichart B, Meiser B, Vigano M et al. European multicenter TAC (FK506) heart pilot study: one-year results-European TAC multicenter heart study group. J Heart Lung Transplant 1998: 17 (8): 775.

20. Friemann S, Feuring E, Padberg W, Ernst W. Improvement of nephrotoxicity, hypertension, and lipid metabolism after conversion of kidney transplant recipients from CsA to TAC. Transplant Proc 1998: 30 (4): 1240.

21. Morris-Stiff G, Baboolal K, Singh J et al. Conversion from CsA to TAC in renal allograft recipients with chronic graft nephropathy: Preliminary report. Transplant Proc 1998: 30: 1245.

22. INTERNATIONAL SOCIETy FOR HEART TrAnsplantaTION. A working formulation for the standardization of nomenclature in the diagnosis of heart and lung rejection: heart rejection study group. J Heart Lung Transplant 1990: 9: 587.

23. BaAn CC, Knoop CJ, van Gelder T et al. Anti-CD25 therapy reveals the redundancy of the intragraft cytokine network after clinical heart transplantation. Transplantation 1999: 67: 870.

24. VAN RIEMSDIJK IC, BAAN CC, KNOOP CJ et al. Quantitative flow cytometry to measure the TNF- $\alpha$ and the IL-2 system after heart transplantation. Transpl Int 2000: 13: S212.

25. BAAn CC, BAlK AHMM, Holweg CTJ et al. Renal failure after clinical heart transplantation is associated with the TGF- $\beta 1$ codon 10 gene polymorphism. J Heart Lung Transplant 2000: 19: 866.

26. DERYNCK R, FENG X-H. TGF- $\beta$ receptor signaling. Biochim Biophys Acta 1997: 1333: F105.

27. Wang T, Danahoe PK, Zervos AS. Specific interaction of type I receptors of the TGF- $\beta$ family with the immunophilin FKBP-12. Science 1994: 265: 674.

28. Zhang JC, Walmsley MW, Moy JV et al. Differential effects on CsA A and TAC on the production of TGFbeta: implications for the development of obliterative bronchiolitis after lung transplantation. Transplant Int 1998: 11: S325.

29. Mohamed MA, Robertson H, Booth TA, BALupuri S, Kirby JA, TALBOT D. TGF-beta expression in renal transplant biopsies: a comparative study between CsA-A and TAC. Transplantation 2000: 69 (5): 1002.

30. Myers BD, Ross JC, Newton LD, Luetscher JA, PERLRoth MG. CsA-associated chronic nephropathy. N Engl J Med 1984: 311: 699. 